Research Article

\title{
Evaluation of Offshore Wind Turbine Tower Dynamics with Numerical Analysis
}

\author{
Begum Yurdanur Dagli $\mathbb{B}$, Yeşim Tuskan, and Ümit Gökkuş \\ Department of Civil Engineering, Manisa Celal Bayar University, Manisa, Turkey \\ Correspondence should be addressed to Begum Yurdanur Dagli; begum.dagli@cbu.edu.tr
}

Received 30 November 2017; Revised 7 February 2018; Accepted 13 March 2018; Published 19 April 2018

Academic Editor: Lyan-Ywan Lu

Copyright (c) 2018 Begum Yurdanur Dagli et al. This is an open access article distributed under the Creative Commons Attribution License, which permits unrestricted use, distribution, and reproduction in any medium, provided the original work is properly cited.

\begin{abstract}
A dynamic behaviour of a cylindirical wind tower with variable cross section is investigated under environmental and earthquake forces. The ground acceleration term is represented by a simple cosine function to investigate both normal and parallel components of the earthquake motions located near ground surface. The function of earthquake force is simplified to apply Rayleigh's energy method. Wind forces acting on above the water level and wave forces acting on below this level are utilized in computations considering earthquake effect for entire structure. The wind force is divided into two groups: the force acting on the tower and the forces acting on the rotor nacelle assembly (RNA). The drag and the inertial wave forces are calculated with water particle velocities and accelerations due to linear wave theory. The resulting hydrodynamic wave force on the tower in an unsteady viscous flow is determined using the Morison equation. The displacement function of the physical system in which dynamic analysis is performed by Rayleigh's energy method is obtained by the single degree of freedom (SDOF) model. The equation of motion is solved by the fourth-order Runge-Kutta method. The two-way FSI (fluid-structure interaction) technique was used to determine the accuracy of the numerical analysis. The results of computational fluid dynamics and structural mechanics are coupled in FSI analysis by using ANSYS software. Time-varying lateral displacements and the first natural frequency values which are obtained from Rayleigh's energy method and FSI technique are compared. The results are presented by graphs. It is observed from these graphs that the Rayleigh model can be an alternative way at the prelimanary stage of the structural analysis with acceptable accuracy.
\end{abstract}

\section{Introduction}

During the last decades, world energy demand is constantly increasing on a global scale. This increase encourages to start exploring new directions in energy production. Renewable energy has become a mainstream subject of these investigations. The production of electrical energy from the wind energy is one of the most cost-effective and feasible projects to reduce the emissions of carbonic gas, preserve the environment, and earn carbon credits [1,2]. Wind plays a predominant role on the scene of clear energy production. Wind turbines can be efficiently used at offshore sites where the higher wind speeds are available compared to those on land [3]. An additional $50 \%$ of electricity can be generated by the same turbine in offshore, compared to that in onshore [4]. However, it is essential that the offshore turbine towers are designed for severe environmental conditions. Wind is considered as design force for onshore structures [5] while wave force is dominant in the offshore environment [6]. Approximately, $70 \%$ of the total environmental forces is composed of wave and current forces affecting the dynamic response [7]. The wave forces can be used as decisive in the design of offshore wind towers $[8,9]$. The combination of wind and wave forces is a common study field, and these investigations are used to design offshore wind towers more stable [10]. On the other hand, the effect of earthquake force on dynamic behaviour of wind turbine structures is investigated as well as the wave and wind forces [11-13].

A typical modern wind turbine can be broken down into its major parts, which are the blade, cabin, and tower. Dynamic analyses of the blade, cabin, and tower are investigated separately by many researchers [14]. The tower that should safely carry both dead loads of equipments and additional loads caused by the environmental forces is the 
critical part of the wind turbine. The tapered, tubular steel towers are the simplest and the most common technical solutions in the last decade [15]. The offshore structures under various environmental force patterns are examined with using numerous analysis techniques in the past [16-18].

Nowadays, it is possible to solve complicated fluidstructure interaction (FSI) problems due to the rapid development of computer software. FSI analyses can be classified as one-way and two-way coupling models. In the one-way coupling type, only the fluid pressure is transferred to the structure solver, and in the two-way coupling type, the displacement of the structure is also transferred to the fluid solver [19].

The one-way FSI analysis in wind turbines is being researched actively [20-22], and the two-way FSI model is being performed $[23,24]$ to analyze structural stability, deformation, and stress due to environmental forces. In addition, semi-empirical models are developed as alternative applications to examine the dynamic behaviour. Rayleigh's energy method is one of the available techniques for vibration analysis. The basic concept of Rayleigh's energy method is single degree of freedom (SDOF). Rayleigh's energy method is used to estimate the natural frequency corresponding to the first mode of vibration by Kim and Han [25], Ward [26], and Cruz and Miranda [27] as in this study.

In this study, the effect of environmental forces and seismic loads on the offshore wind tower behaviour is performed with two various approaches. Wind force is divided into force acting on the tower and equipments. The tower subjected to wave forces represented by the linear wave theory. The Morison equation is employed to obtain lateral wave forces. In the first approach, the displacement function of the wind tower is determined by the SDOF model. Dynamic vibration is investigated with Rayleigh's energy method by using this displacement function. The equation of motion that is representing dynamic behaviour is integrated by using the fourth-order Runge-Kutta method. The values of displacements, stresses, and natural frequencies are established under wind, wave, and earthquake forces. In the second approach, numerical simulations are also utilized in a 3D finite element model in the framework of ANSYS by evaluating FSI. Two-way FSI analysis is performed by connecting the mechanical system and another participant Fluent system to a system coupling component system [28]. The variations of displacements and natural frequency values are compared for the results of the finite element model (FEM) and Rayleigh model.

\section{Description of Structure}

The wind tower is selected as similar to the one used in Van der Woude and Narasimhan [13] for this study, consisting of uniform and homogeneous material that is planned to be fixed to the seabed. The outside diameter of the tower is $4.00 \mathrm{~m}$ at the base and $1.50 \mathrm{~m}$ at the top and the constant wall thickness of $30 \mathrm{~mm}$. The material properties are chosen to represent the steel, with Young's modulus of $21 \times 10^{7} \mathrm{kN} / \mathrm{m}^{2}$, Poisson's ratio of 0.3 , and density of $78.50 \mathrm{kN} / \mathrm{m}^{3}$. For steel,

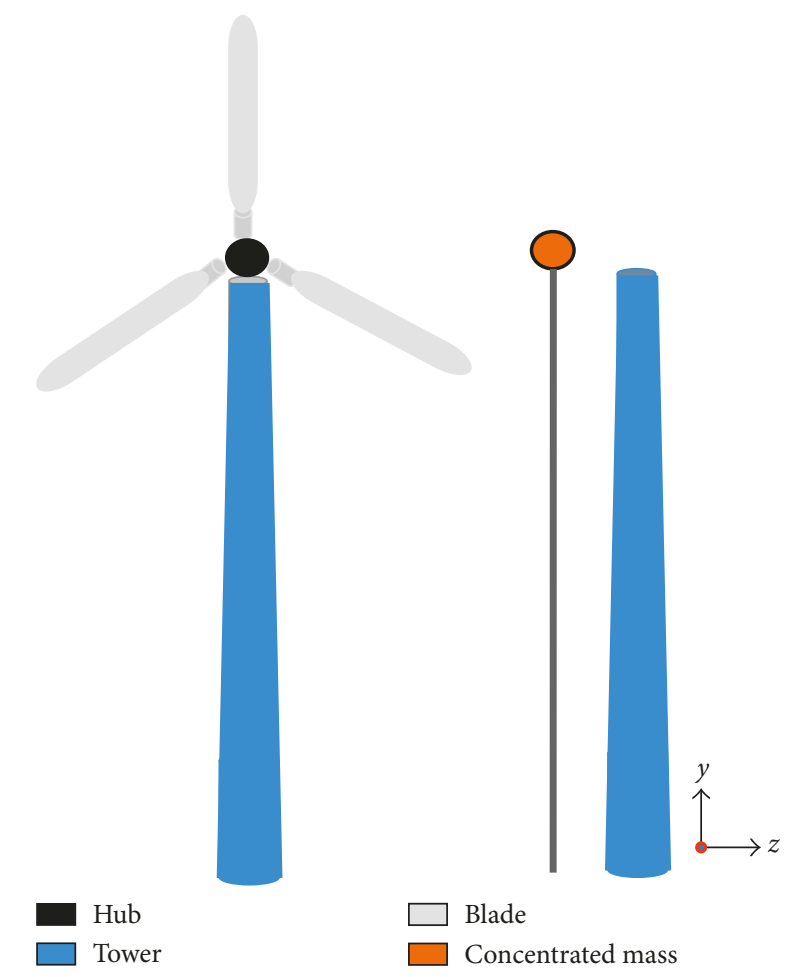

Figure 1: The model of the wind turbine.

it is assumed that the material will comply with the associated Prandtl-Reuss flow rule and von Mises yield criterion [29]. The reinforced fiberglass polyester material is used for the blades which are fixed on pitched bearings that can be feathered $90^{\circ}$ for shutdown purposes.

The hub height of the wind turbine is $65 \mathrm{~m}$. Fixed and free supports are placed at the boundaries. The tower construction carries the weight of the nacelle, hub, and the rotor blades which is $83,000 \mathrm{~kg}$. Young's modulus of the blade material is $65 \times 10^{6} \mathrm{kN} / \mathrm{m}^{2}$, and the value of density is $21.00 \mathrm{kN} / \mathrm{m}^{3}$. The blade length is $24 \mathrm{~m}$, hub diameter is $6 \mathrm{~m}$, and swept area of the blades is $624 \mathrm{~m}^{2}$. The structural model is presented in Figure 1.

Apart from the equipment, only the wind tower is considered in the structural analysis. The dead weight of the equipment (hub, nacelle, and blade) is implemented at the top of the tower. The dead weight, earthquake, wind, and wave forces in the global $x$ direction are taken into account in the solutions.

\section{Description of Forces Acting on Structure}

The structural modal is designed by considering dead loads $(N)$ as well as wind $\left(F_{\mathrm{w}}\right.$ and $\left.F_{\text {aero }}\right)$, wave $\left(F_{\mathrm{H}}\right)$, and earthquake forces $\left(F_{\text {eqk }}\right)$ as given in Figure 2. When determining the dynamic behaviour of the wind tower, two different strategies are used.

The environmental forces (wind and wave) and earthquake force are externally assigned to the tower in Rayleigh's energy method. 


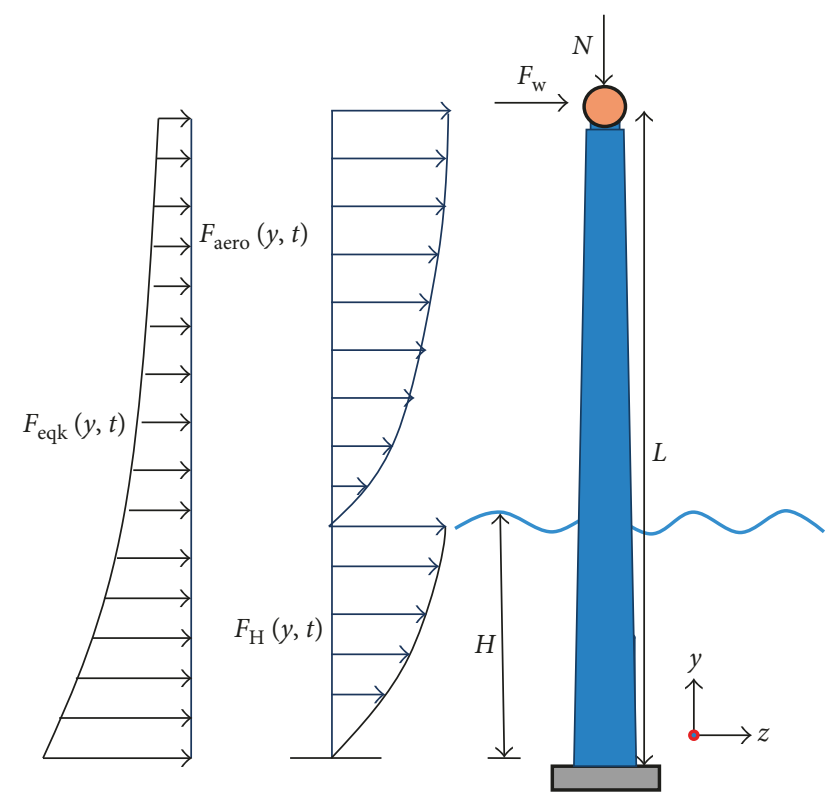

FIgURE 2: The forces acting on the wind tower.

In the finite elements analysis, velocity profiles that defined as boundary conditions are used to compute these mentioned forces. The effect of environmental forces and earthquake force in designing is explained in the other sections.

3.1. Wind Forces. The wind forces acting on the Rotor Nacelle Assembly (RNA) and associate instrumentation can be considered as a concentrated force [30] and can be determined with an equation similar to that for the calculation of hydrodynamic forces:

$$
F_{\text {aero }}=\int_{d}^{L} \frac{1}{2} C_{\text {aero }} \rho_{\text {air }} A_{(y)} V_{\text {air }(y, t)}^{2} d y,
$$

where $F_{\text {aero }}$ is the wind force acting on the structure, $\rho_{\text {air }}$ is the density of air, $C_{\text {aero }}$ is the aerodynamic coefficient (shape, surface and dependent) which is considered as 0.50 for the cylindrical sections, $A_{(y)}$ is the exposed area of the section, and $V_{\text {air }(y, t)}$ is the wind velocity which is presented by the following equation [31]:

$$
V_{\text {air }(y, t)}=V_{\text {ref }} k_{\mathrm{r}} \ln \left(\frac{y}{z_{\mathrm{r}}}\right),
$$

where $V_{\text {ref }}$ is the basic parameter called as reference wind velocity. The values of time-dependent wind velocity are presented in Figure 3.

The mean value of wind velocity is determined as $18 \mathrm{~m} / \mathrm{s}$. The roughness coefficient describes the effect terrain roughness and is defined by a logarithmic law [32]. In this study, the terrain factor $k_{\mathrm{r}}$ is assumed as 0.17 and the length of roughness $z_{0}$ is considered as 0.01 .

3.2. Wave Forces. The wave parameters were utilized to compute the hydrodynamic wave forces acting on the wind

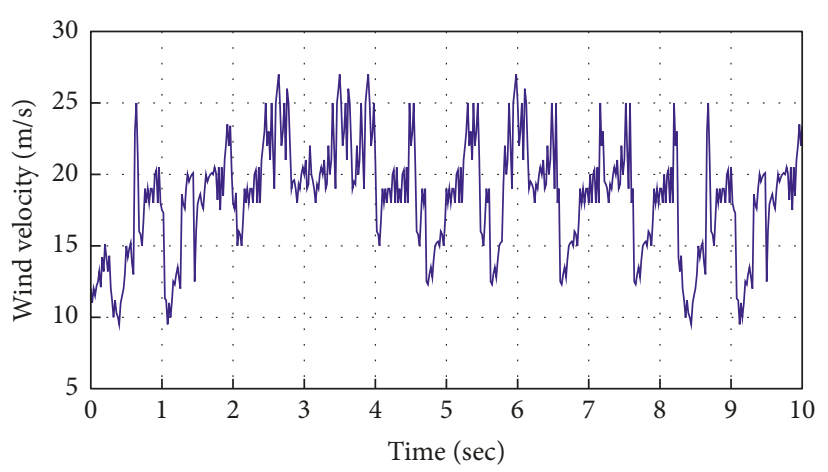

FIgURE 3: Time-varying reference wind velocity.

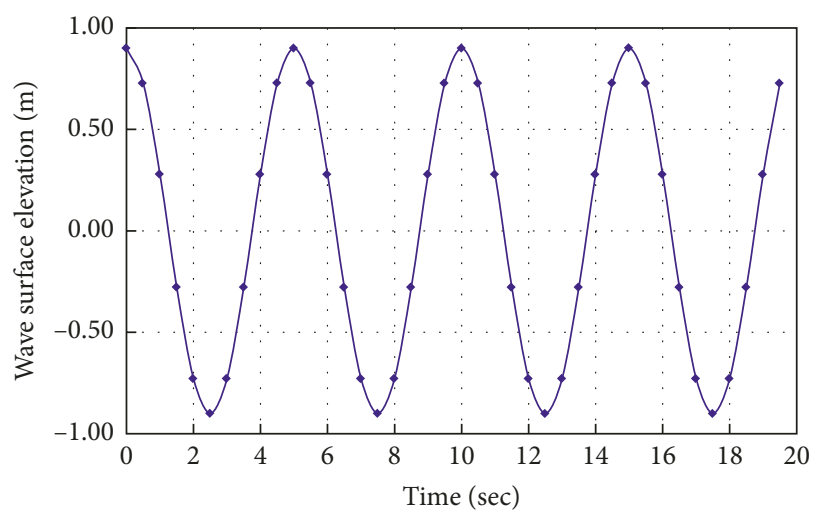

FIgURE 4: Regular wave surface elevations.

tower. The wave height $H$, wave length $L$, and wave period Tare the major wave parameters [33, 34]. Moreover, different environmental conditions were characterized by using water depth $d$ which is applicable to determine the wave theories [35].

In this study, the offshore environment conditions are modelled in the numerical analysis by the linear wave theory. The parameters are considered as $H=1.80 \mathrm{~m}, T=5 \mathrm{~s}$, $L=38.90 \mathrm{~m}$, and $d=20 \mathrm{~m}$. As seen in Figure 4, the wave surface is determined based on the potential flow approach, by linear wave theory. The sea water characteristics were chosen as fluid properties, with a density of $1025 \mathrm{~kg} / \mathrm{m}^{3}$ and a dynamic viscosity of $0.0015 \mathrm{Ns} / \mathrm{m}^{2}$.

The orbital motion of the water particle is significant for the horizontal hydrodynamic force. The force consists of two components: a drag force $\left(F_{\mathrm{D}}\right)$ and an inertial force $\left(F_{\mathrm{I}}\right)$ [36]. The drag force and the inertial force are proportional to the fluid particle velocity and fluid particle acceleration, respectively. The equations of fluid particle velocity $(u)$ and acceleration $(\dot{u})$ according to linear wave theory are given as follows:

$$
\begin{aligned}
& u=\frac{\pi H}{T} \frac{\cosh [(2 \pi / L)(d+y)]}{\sinh 2 \pi d / L} \cos \theta, \\
& \dot{u}=-\frac{2 \pi^{2} H}{T^{2}} \frac{\cosh [(2 \pi / L)(d+y)]}{\sinh 2 \pi d / L} \cos \theta,
\end{aligned}
$$

where $\theta=(2 \pi / L) x-(2 \pi / L) t$ and is called as the phase angel. The total lateral hydrodynamic force $\left(F_{\mathrm{H}}\right)$, which 
includes drag and inertial forces, is obtained by the Morison equation as follows:

$$
\begin{aligned}
& F_{\mathrm{D}}=\int_{-d}^{\eta} \frac{1}{2} \rho_{\mathrm{w}} C_{\mathrm{d}} D_{(y)} u_{(y, t)}\left|u_{(y, t)}\right| d y, \\
& F_{\mathrm{I}}=\int_{-d}^{\eta} \frac{1}{4} \pi \rho_{\mathrm{w}} C_{\mathrm{M}} D_{(y)}^{2} \dot{u}_{(y, t)} d y .
\end{aligned}
$$

These two components are added together to give the Morison equation:

$$
\begin{aligned}
F_{\mathrm{H}}= & \int_{-d}^{\eta} \frac{1}{2} \rho_{\mathrm{w}} C_{\mathrm{d}} D_{(y)} u_{(y, t)}\left|u_{(y, t)}\right| d y \\
& +\int_{-d}^{\eta} \frac{1}{4} \pi \rho_{\mathrm{w}} C_{\mathrm{M}} D_{(y)}^{2} \dot{u}_{(y, t)} d y,
\end{aligned}
$$

where $\rho_{\mathrm{w}}$ is the salty water density, $D$ is represented as the diameter of the tower. As seen in (4) and (5), the drag force coefficient $C_{\mathrm{d}}$ and inertial force coefficient $C_{\mathrm{M}}$ are needed to calculate the force components. In this study, the values of $C_{\mathrm{d}}$ and $C_{\mathrm{M}}$ are assumed as 2.4 and 0.7, respectively [37].

3.3. Earthquake Forces. The dynamic analyses predicting the behaviour of the tower to either wind, wave, or seismic excitation are complicated due to the fact that the structure is partially immersed in water.

The acceleration, or the rate of change of the velocity of the waves setting the structure in motion, determines the percentage of the structure mass or weight that must be dealt with as a horizontal force [38]. Because of the inertial force formula, acceleration is a key factor in determining the forces on a tower, but a more significant measure is acceleration combined with duration, which takes into account the impact of earthquake forces over time. In this study, the acceleration of earthquake is considered as follows:

$$
\ddot{V}_{\mathrm{g}}(t)=\cos (\pi t) .
$$

Because sine and cosine acceleration pulses are physically realizable and resemble in several occasions, the fault parallel and the fault normal component of motions are recorded near the source of strong earthquakes [39]. A forcing function is derived for the earthquake model by writing the equations of motion in an accelerating frame of reference coincident with the base motion.

\section{Analysis of the Wind Tower Response}

Rayleigh's energy method and ANSYS FSI analysis are utilized to obtain natural frequencies neglecting the dynamic effects of blades on the tower [13]. The weight of the nacelle and the rotor blades and wind loads acting on these equipments are implementing on the top of the turbine tower.

All problems in structural dynamics can be formulated based on the above equation of motion [40]:

$$
m \ddot{Z}(t)+c \dot{Z}(t)+k Z(t)=F(t),
$$

where $Z$ is the coordinate vector, $m$ is the mass, $c$ and $k$ are the coefficients of damping and stiffness, respectively. The external force is equalized to the inertial, damping, and restoring forces. Moreover, $\dot{Z}(t)$ is the velocity, $\ddot{Z}(t)$ is the acceleration, and $F(t)$ is the total force. $(\cdot)$ denotes derivative with respect to time $\mathrm{d} / \mathrm{dt}$.

4.1. Displacement Function. When motion is analyzed in a specific direction, the dynamic system is processed as a SDOF. Accordingly, we can define the displacement function as

$$
v(y, t)=\psi(y) Z(t),
$$

where $\psi(y)$ is a shape function and $Z(t)$ is the displacement. By substituting (9) into (8), the equation of motion of the tower can be reconstructed and thus can be given as follows:

$$
\begin{gathered}
\left(\int_{0}^{L} m(y) \psi(y)^{2} d y\right) \ddot{Z}(t)+\left(a_{1} E \int_{0}^{L} I(y) \psi^{\prime \prime}(y)^{2} d y\right) \dot{Z}(t) \\
+\left(E \int_{0}^{L} I(y) \psi^{\prime \prime}(y)^{2} d y-N \int_{0}^{L} \psi^{\prime}(y)^{2} d y\right) Z(t) \\
=F_{\mathrm{w}}+F_{\text {aero }}(t) \int_{0}^{L-H} y_{\mathrm{a}}(y) \psi(y) d y+F_{\mathrm{H}}(t) \\
\quad \times \int_{0}^{H} y_{\mathrm{H}}(y) \psi(y) d y-\ddot{V}_{\mathrm{g}}(t) \int_{0}^{L} m(y) \psi(y) d y .
\end{gathered}
$$

The dynamic analysis is performed considering the external forces acting on the wind tower when $t=0$ by using SAP software. And the initial shape function is obtained in accordance with the displacement curve as

$$
\psi(y)=1.62\left(\frac{y}{L}\right)^{3}-3.11\left(\frac{y}{L}\right)^{2}+2.49 \frac{y}{L} .
$$

The examination of the exact solution of linear ordinary differential equations is carried out utilizing the associated classical boundary conditions.

Fixed support is considered as the bottom condition and free support is assumed at the top of the tower. The boundary conditions are defined as follows:

$$
\begin{aligned}
& \text { At } y=0 \quad \psi \rightarrow 1.62\left(\frac{y}{L}\right)^{3}-3.11\left(\frac{y}{L}\right)^{2}+2.49 \frac{y}{L}=0, \\
& \text { At } y=0 \quad \psi^{\prime} \rightarrow 4.86 \frac{y^{2}}{L^{3}}-6.22 \frac{y}{L^{2}}+\frac{2.49}{L}=0 .
\end{aligned}
$$

The equation of motion of the SDOF system is determined by substituting the shape function as below:

$$
\begin{aligned}
0.0505 L \ddot{Z}(t)+3.563 \frac{c E}{L^{3}} \dot{Z}(t)+\left(3.563 \frac{E}{L^{3}}-1.285 \frac{N}{L}\right) Z(t) \\
=140732-33.92 \sin (1.26 t)+2.59 \cos (1.26 t) \\
\cdot|\cos (1.26 t)|-0.0756 \ddot{V}_{\mathrm{g}}(t) L,
\end{aligned}
$$




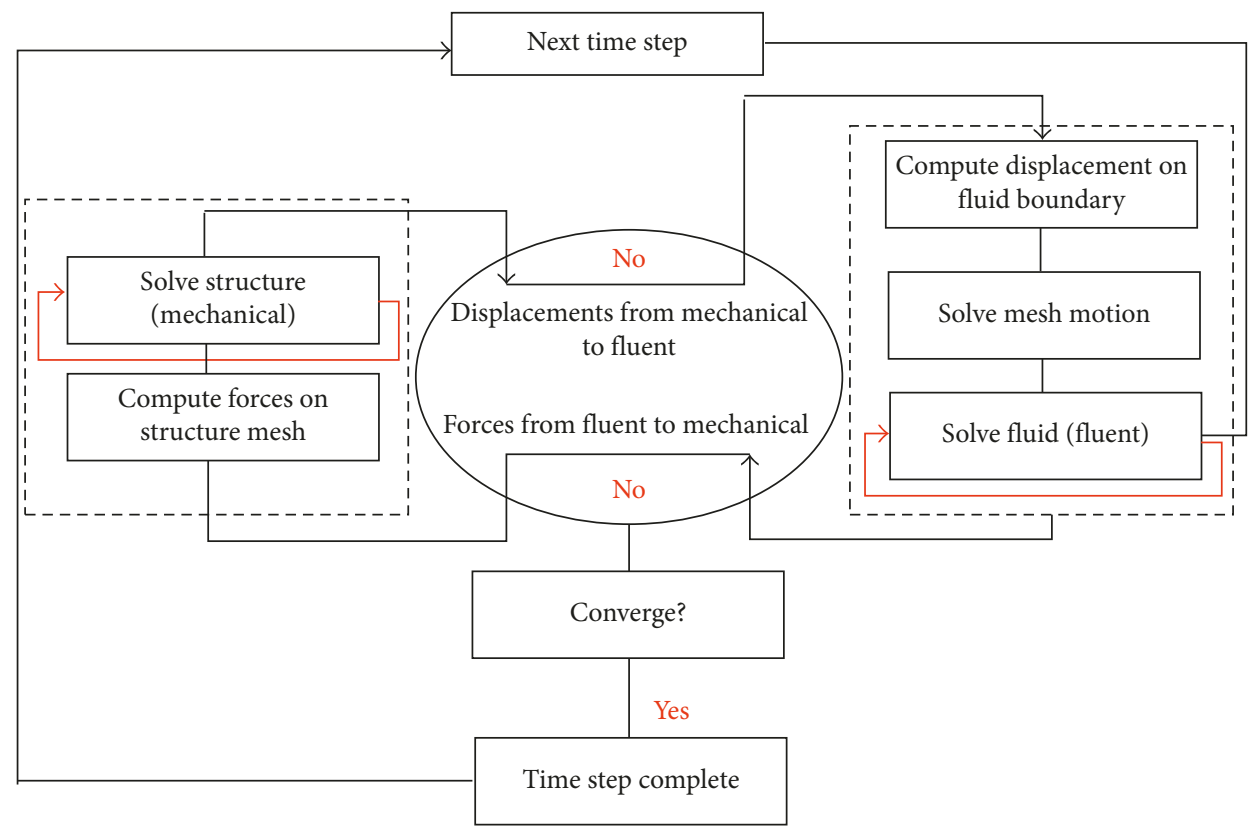

FIGURE 5: Flow chart for multifield simulations with ANSYS.

where the length of the turbine tower is $L$, Young's modulus of the material is $E$, the axial force is $N$, the damping coefficient of the system is $c$ and are assumed as $65 \mathrm{~m}$, $2.1 \times 10^{11} \mathrm{~N} / \mathrm{m}^{2}, 8.3 \mathrm{kN}$, and 0.005 , respectively. The right side of (13) presents the total wind force, hydrodynamic force, and earthquake force terms. Substituting the values of forces and material properties, the second order derivation of displacement $\ddot{Z}(t)$ is obtained as

$$
\ddot{Z}(t)=\frac{140732-33.92 \sin (1.26 t)+2.59 \cos (1.26 t) \cdot|\cos (1.26 t)|-0.0756 \cos (\pi t) L-0.02 \dot{Z}(t)-4.04 Z(t)}{0.0505} .
$$

The fifth-order Runge-Kutta method is used to solve (14). The initial conditions are considered as

$$
\begin{aligned}
& \text { when } t=0 \text { at } y=0 \Rightarrow Z(0)=0 \text { and } \dot{Z}(0)=0, \\
& \text { when } t=0 \text { at } y=L \Rightarrow \ddot{Z}(0)=0 .
\end{aligned}
$$

The displacement function based on time-varying, $Z(t)$, is generated with boundary conditions.

Then, the displacement function based on locationvarying, $v(y, t)$, is obtained as

$$
\begin{aligned}
v(y, t)= & {\left[1.62\left(\frac{y}{L}\right)^{3}-3.11\left(\frac{y}{L}\right)^{3}+2.49 \frac{y}{L}\right] } \\
& \times\left[\frac{Z_{0}}{\sqrt{t+1}} \sin (\pi \omega t)+\left(0.12 \sqrt{1+e^{-t}} \cos (\pi \omega t)\right)\right],
\end{aligned}
$$

where $Z_{0}$ is the value of the maximum displacement and $\omega$ is the natural frequency. The displacement function (16) described above is used in Rayleigh's energy method to derive the natural frequency.

4.2. Rayleigh's Energy Method. The dynamic behaviour of the offshore structures can be characterized in terms of one or more natural frequencies. Rayleigh's energy method is one of the available techniques for determining the natural frequency [41]. This method, which requires a displacement function, reduces the dynamic system to a single degree of freedom (SDOF) system.

Rayleigh's energy method is a technique for finding natural frequencies by equating the maximum kinetic energy of a system with the maximum potential (often strain) energy. The potential energy of the wind tower can be given as

$$
U=\frac{1}{2} Z_{0}^{2} \int_{0}^{L} E I(y)\left(\frac{\partial^{2} v}{\partial y^{2}}\right)^{2} d y .
$$

The maximum potential energy is attained when the mass reaches its maximum displacement as follows:

$$
u_{\max }=\frac{1}{2} Z_{0}^{2} \int_{0}^{L} E I(y)\left[\psi^{\prime \prime}(y)\right]^{2} d y .
$$

The kinetic energy of nonuniform mass distribution is presented as

$$
T=\frac{1}{2} \int_{0}^{L} m(y)(\dot{\nu})^{2} d y .
$$

The maximum kinetic energy is attained when the mass passes the equilibrium position as given below: 


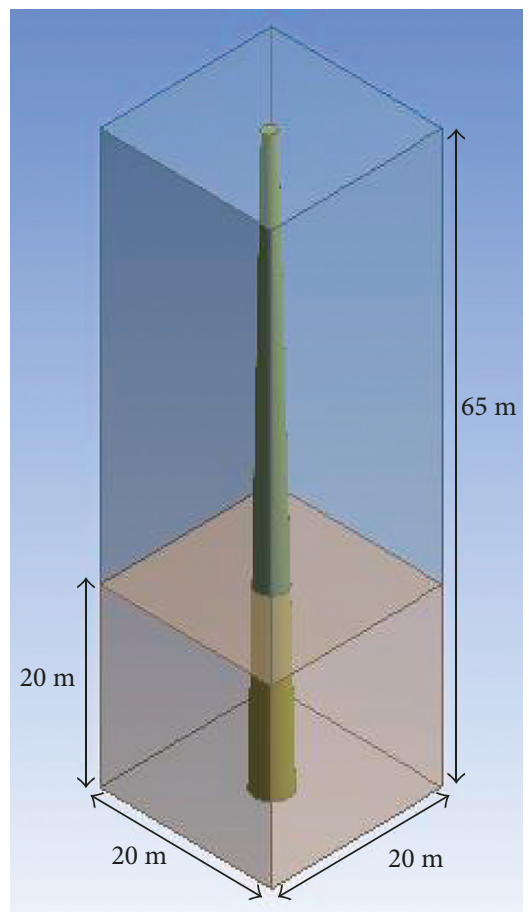

(a)
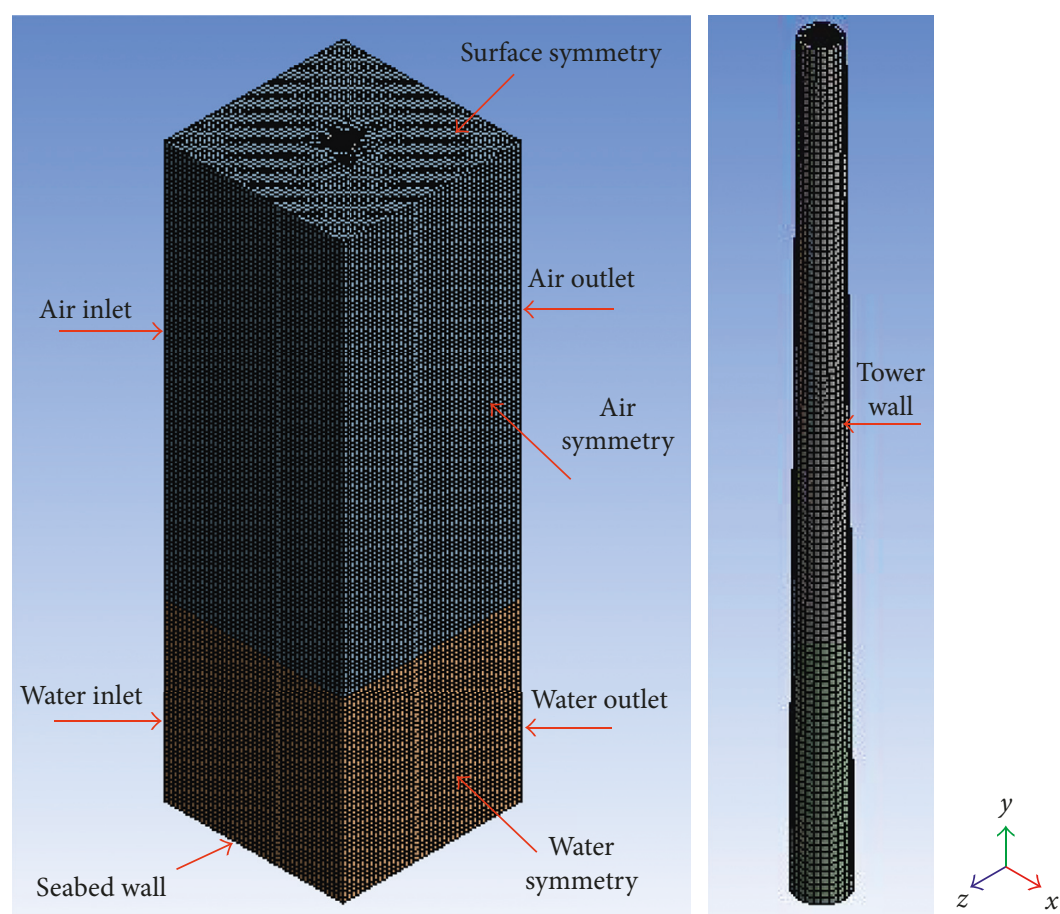

(b)

Figure 6: (a) Unmeshed domains. (b) Meshed domains.

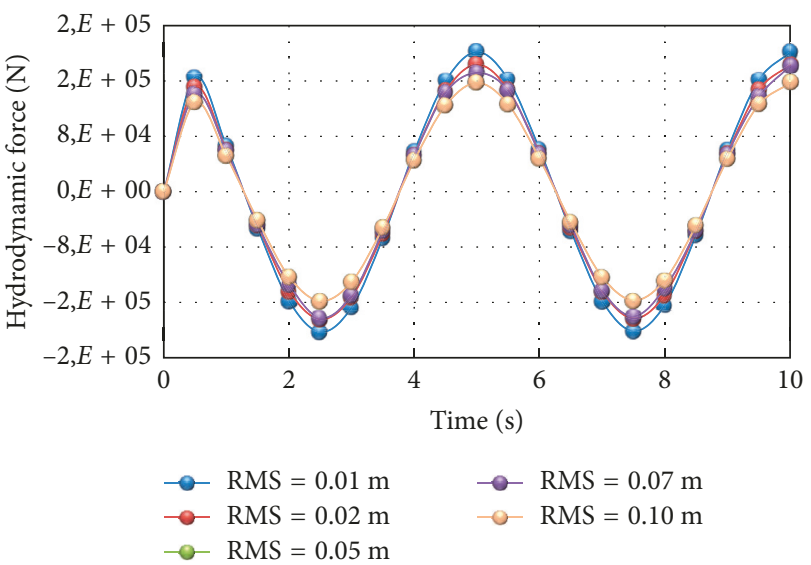

Figure 7: Comparison of hydrodynamic forces for the mesh convergence study.

$$
T=\frac{1}{2} Z_{0}^{2} \omega^{2} \int_{0}^{L} m(y)[\psi(y)]^{2} d y .
$$

The natural frequency is obtained by equalizing kinetic and potential energy

$$
\omega^{2}=\frac{\int_{0}^{L} E I(x)\left[\psi^{\prime \prime}(y)\right]^{2} d y}{\int_{0}^{L} m(y)[\psi(y)]^{2} d y} .
$$

The method described above is checked with the computer-aided FSI method (ANSYS FSI).

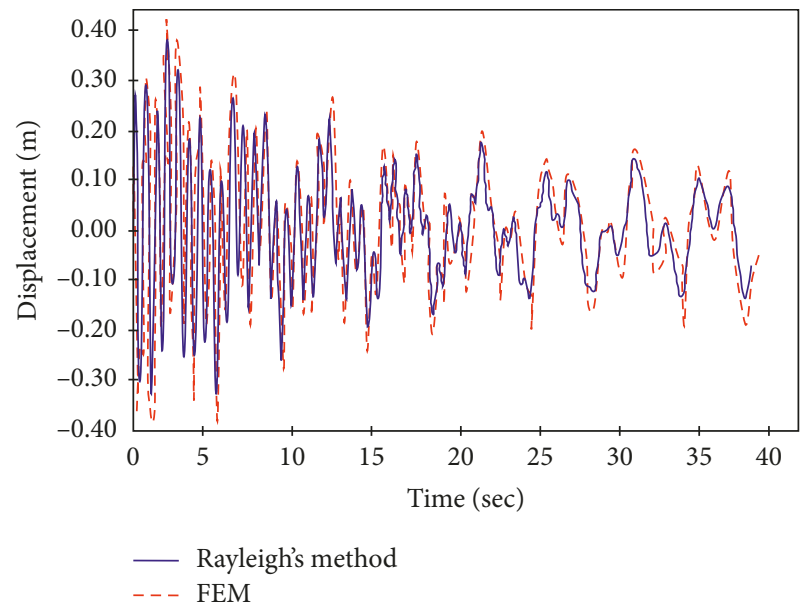

Figure 8: Time-varying displacement values of the wind tower.

4.3. Computer-Aided FSI Analysis. Two disciplines involved in the offshore wind tower analysis are fluid dynamics and structural dynamics. Coupled systems and formulations are applicable to this FSI problem which includes multiple domains. In this study, two-way coupled simulations have been performed by using ANSYS software. On the fluid side, ANSYS Fluent is used and on the structure side ANSYS Mechanical. ANSYS System Coupling is used to define contact surfaces. The ANSYS Fluent analysis results, at the fluid-structure interface, are transferred to the mechanical model and applied as loads. Within the same analysis, the subsequently calculated displacements at the 


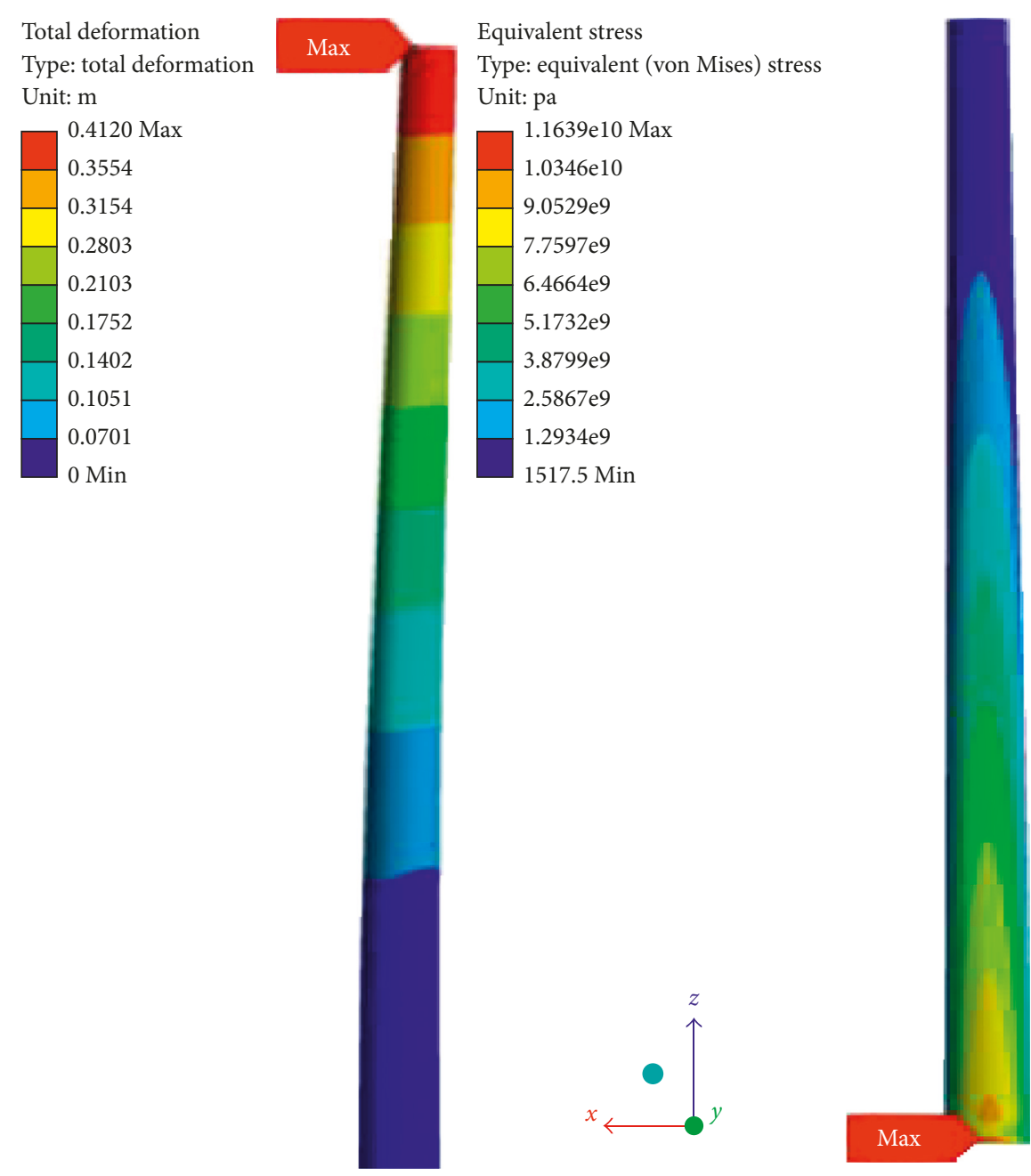

FIgURE 9: The distribution of the von Mises stress values.

fluid-structure interface are transferred back to the ANSYS Fluent analysis.

In this study, the modelling process starts in ANSYS Workbench multifield when the simulation is performed between transient structural (ANSYS Mechanical) and fluidflow (ANSYS Fluent). Both models are developed independently. Independent mesh, boundary conditions, analysis options, and output options are used for each model. Initial analysis is performed for the structural part with the specified fundamental properties (density, Young's modulus, and Poisson's ratio) for the structure. The flow chart for multifield simulations with ANSYS is given in Figure 5.

In the mechanical application, the structural part is meshed and the fluid part is suppressed. Appropriate names are assigned to all inlet, outlet, and side surfaces and symmetry planes in Fluent. The ANSYS mapping is done to interpolate loads between dissimilar meshes on either side of the coupling interface. This model will be used to transfer the displacement applied at the boundary surface to the other nodes.

The effect of wave and wind forces on structural behaviour of the wind tower is considered with a nonlinear numerical model based on the finite volume method with the ANSYS Fluent analysis program [40]. The dimensions of the air domain are $20 \times 20 \times 45 \mathrm{~m}$ and the water domain is $20 \times 20 \times 20 \mathrm{~m}$ in directions $x, y$, and $z$, respectively (Figure 6).

The wind tower is surrounded by a box with $5 \times 5 \times 65 \mathrm{~m}$ which is created to make a refined mesh around the structural members. The CFD mesh of this study is a hybrid mesh combination of tetrahedral and prism layers. The mesh distance of the fluid model in the box is taken as $0.01 \mathrm{~m}$. The mesh distance is $0.30 \mathrm{~m}$ in the remaining parts of the model. To calculate deformation of the boundary between fluid and solid, the displacement diffusion algorithm is used. The connections between the nodes are modelled as springs. This stiffness can change from node to node; near boundaries, though, the mesh stiffness is set very high. The mesh distance of the fluid model is taken as $0.02 \mathrm{~m}$ in contact surfaces with the solid model. The computational structural mechanics (CSM) finite element mesh is used for the tower. The same value of wall thickness $(0.035 \mathrm{~m})$ is selected for node distances in the solid model. The fluid (water and air) and solid domains contain approximately 2.12 million and 51.000 cells, respectively.

Five meshes with different resolution as shown in Figure 7 has been created in order to perform a mesh convergence study. Refined mesh sizes (RMSs) are considered as $0.01 \mathrm{~m}, 0.02 \mathrm{~m}, 0.05 \mathrm{~m}, 0.07 \mathrm{~m}$, and $0.10 \mathrm{~m}$. Figure 7 shows 

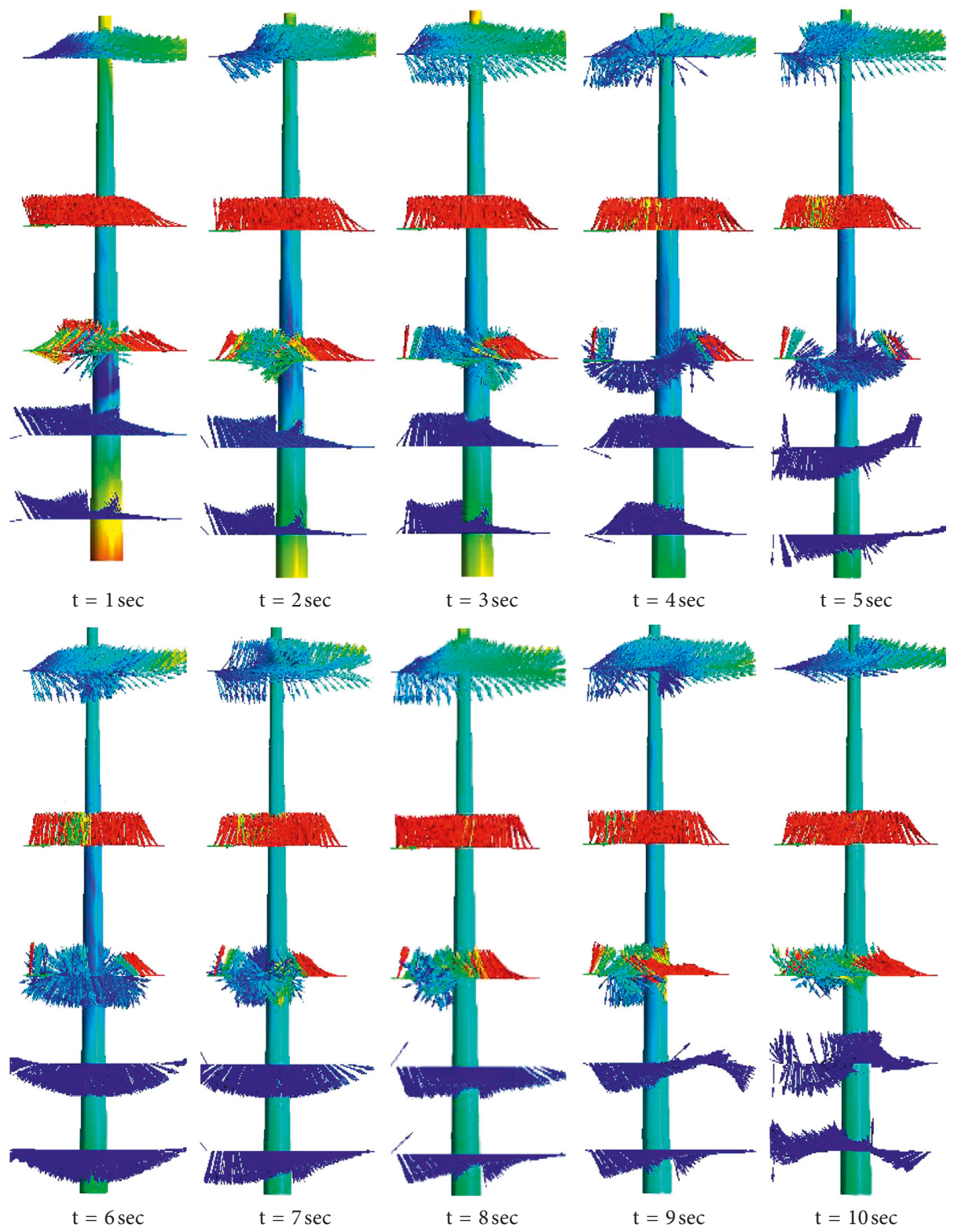

Figure 10: Velocity vectors of fluid domain around the wind tower.

the comparison of horizontal hydrodynamic forces $\left(F_{\mathrm{H}}\right)$. The maximum difference of $8 \%$ is observed between the peak values. So, it can be concluded from the comparison that the solution (force) is reasonably independent of the mesh resolution.

The flow involves the free surface between air and water that is solved using VOF (volume of fluid) formulation [40]. The VOF model depends on the Euler-Euler approach. The general form of the transport equation can be given as

$$
\frac{\partial(\rho \varphi)}{\partial t}+\operatorname{div}(\rho \varphi u)=\operatorname{div}(\Gamma \operatorname{grad} \varphi)+S_{\varphi},
$$

where $\rho$ is the density and $u$ and $S$ are the velocity and momentum source terms, respectively. The variable $\varphi$ can be replaced by any scalar quantity, and $\Gamma$ is the diffusion coefficient [42]. The effects of turbulence are modelled using
RANS (Reynolds-averaged Navier-Stokes) simulation. The realizable $k-\varepsilon$ turbulence model is represented by the transport equations as follows [43]:

$$
\begin{aligned}
\frac{\partial}{\partial t}(\rho k)+\frac{\partial}{\partial x_{j}}\left(\rho k u_{j}\right)= & \frac{\partial}{\partial x_{j}}\left[\left(\mu+\frac{\mu_{\mathrm{t}}}{\sigma_{\mathrm{k}}}\right) \frac{\partial k}{\partial x_{j}}\right] \\
& +G_{\mathrm{k}}+G_{\mathrm{b}}-\rho \varepsilon-Y_{\mathrm{M}}+S_{\mathrm{k}},
\end{aligned}
$$

$$
\begin{aligned}
\frac{\partial}{\partial t}(\rho \varepsilon)+\frac{\partial}{\partial x_{j}}\left(\rho \varepsilon u_{j}\right)= & \frac{\partial}{\partial x_{j}}\left[\left(\mu+\frac{\mu_{\mathrm{t}}}{\sigma_{\varepsilon}}\right) \frac{\partial \varepsilon}{\partial x_{j}}\right]+\rho C_{1} S_{\varepsilon} \\
& -\rho C_{2} \frac{\varepsilon^{2}}{k+\sqrt{\nu \varepsilon}}+C_{1 \varepsilon} \frac{\varepsilon}{k} C_{3 \varepsilon} G_{\mathrm{b}}+S_{\varepsilon},
\end{aligned}
$$



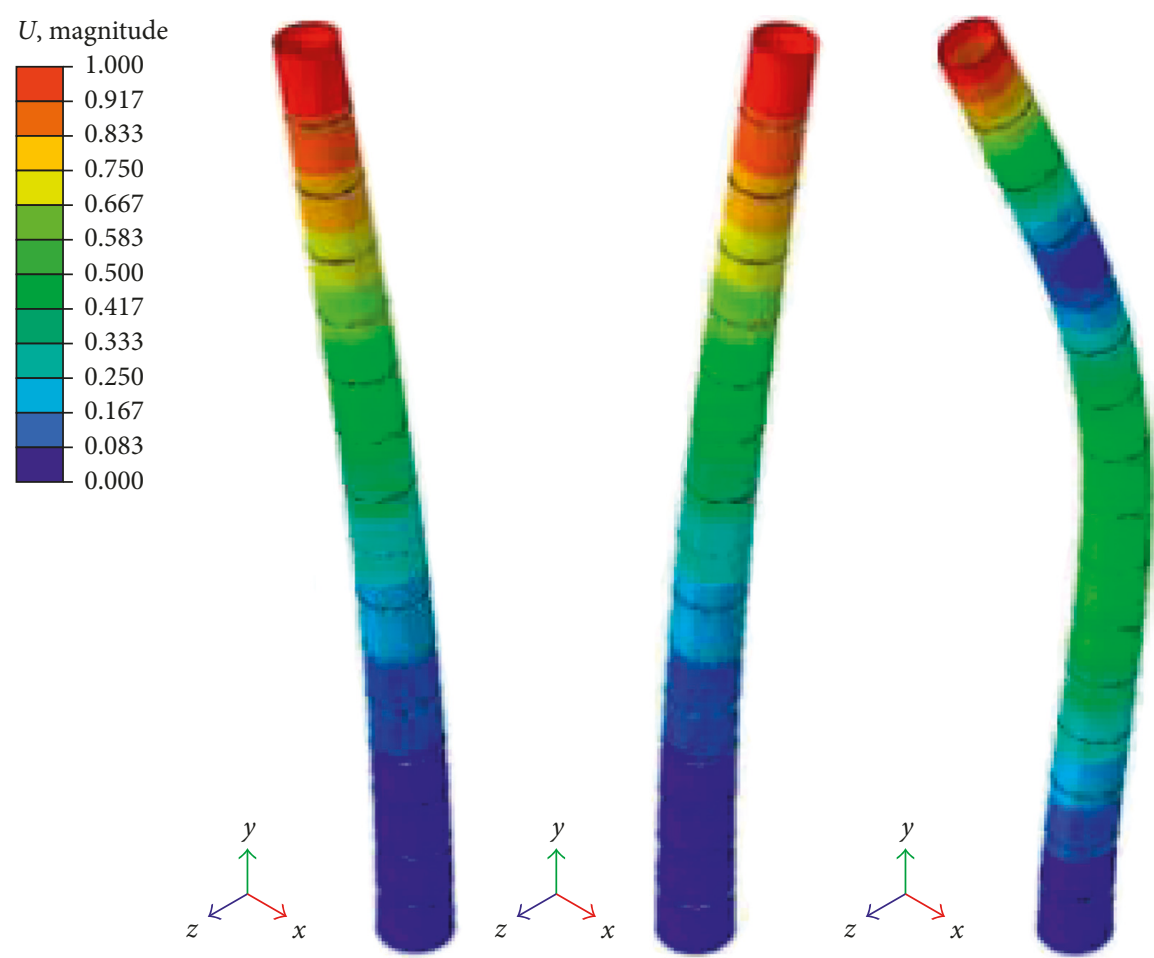

FIGURE 11: First three vibration modes of the wind tower.

where $k$ is the turbulent kinetic energy, $\varepsilon$ is the turbulence dissipation rate, $\mu_{\mathrm{t}}$ is the turbulent viscosity, $C_{1}, C_{1 \varepsilon}$, and $C_{2}$ are the constants, and $\sigma_{\mathrm{k}}$ and $\sigma_{\varepsilon}$ are the Prandtl numbers. $G_{\mathrm{k}}$ represents the generation of turbulence kinetic energy due to the mean velocity gradients, $G_{b}$ represents the generation of turbulence kinetic energy due to buoyancy, $Y_{\mathrm{M}}$ is the contribution of fluctuating dilation, and $i, j$ are the tensor indices. The Fluent CFD code and ANSYS transient structural FEM code are applied concurrently for the following boundary conditions as illustrated in Figure 6.

The transport equations are discretized in both space and time. Explicit time integration is used for temporal discretization. The calculations for the structure side are based on the impulse conservation. The model utilizes the equation of motion presented in (8). The earthquake force is considered besides the environmental forces in structural dynamic analysis. The vibration characteristics of a structure while it is being designed are investigated by modal analysis. In a mathematical sense, the computation of natural frequencies and mode shapes is equivalent with the solution of an eigenvalue problem [42]. In this study, the QR damped method is used as an eigensolver in ANSYS to compute natural frequencies.

At the boundary between fluid and solid, the fluidstructure interface, information for the solution is shared between the fluid solver and structure solver. The information of pressures and displacements is exchanged between the domains dependent on the coupling method. For two-way coupling calculations, fluid and wind pressure is transferred to the structure and the displacement of the structure is also transferred to the fluid solver [19]. The properties of steel material are employed for the wind tower. Salty water and air properties are defined for fluid domain.

The system is solved iteratively until the changes in the flow forces and the structural displacements fall below a prescribed amount.

\section{Numerical Results}

The examination of the exact solution of the linear ordinary differential equation is carried out by the Runge-Kutta method utilizing the associated boundary conditions.

Hence, the time-varying displacement values which are obtained by using Rayleigh's energy method and FEM are compared in Figure 8. Analyses are observed during 40 seconds, and the time step size is assumed as 0.01 second.

As seen in Figure 8, the maximum value of the displacement is obtained as $0.412 \mathrm{~m}$ for the FEM method and $0.382 \mathrm{~m}$ for Rayleigh's energy method. The maximum displacement is obtained at the top of the cylindrical structure.

The von Mises stress and displacement values according to the FEM analysis are presented in Figure 9.

The maximum von Mises stress value is $1.1639 \times 10^{10} \mathrm{~Pa}$. These figures illustrate that the stress values on the tower surface are found to be higher closer to the seabed. The hydrodynamic wave and wind velocities calculated by the CFD analysis are shown in Figure 10 for 10 seconds.

Hydrodynamic forces that are transferred from the fluid domain to the solid domain are determined by analysis program according to these hydrodynamic velocities. The natural torsional frequency values and vibration modes are computed by eigenvalue analysis. The dominant vibration modes are given in Figure 11. 
There is a predominance of translational displacements towards the " $x$ " axis in the first vibration mode. The first torsional natural frequency value is determined as $9.012 \mathrm{~Hz}$ (bending frequency as $0.691 \mathrm{~Hz}$ ) by (21) and $9.440 \mathrm{~Hz}$ (bending frequency as $0.711 \mathrm{~Hz}$ ) by FEM analysis. Environmental forces effect on the behaviour of the structure is investigated by several researchers, similar to our study $[44,45]$. The transfer matrix method was used for dynamic analyzing of the large-scale wind turbine steel tower and the natural frequency value was obtained as 0.9765 for the first mode by Meng and Zhangqi [45]. Zhao et al. investigated the influence of the diameter, thickness, taper angle, nacelle and rotor mass, and offset of mass on the inherent characteristic of the tower on the dynamic behaviour. The basic bending frequency and torsional frequency values were obtained as $0.529 \mathrm{~Hz}$ and $5.142 \mathrm{~Hz}$, respectively, by the Rayleigh method. The proposed methods in this paper showed good agreements with dynamic analysis results by the published literatures.

\section{Conclusions}

The dynamic behaviour of the wind tower when it is subjected to environmental and seismic loads is investigated utilizing two various approaches. Environmental forces consist of regular wind and wave loads. Wind force acting on the tower is determined due to Eurocode velocity. Linear wave theory is adopted to design marine conditions. The Morison equation is employed to obtain lateral wave forces. The tower is designed by using the single degree of freedom (SDOF) model. In the first approach, Rayleigh's energy method which is the most popular analytical method for vibration analysis of a single degree of freedom system is used. Rayleigh's energy method is based on the principle of conservation of energy. Dynamic vibration is investigated by using the displacement function in presence of the fourthorder Runge-Kutta method. The values of displacements and natural frequency are established under wind, wave, and earthquake forces. In the second approach, numerical simulations are applied with the framework of ANSYS via FSI. Two-way FSI analysis is performed to compare the results. The forces from fluid to structure and displacements from structure to fluid are considered with the two-way FSI analysis.

When the first natural frequency values of the tower were investigated, it was established that differences are not exceeding $4.77 \%$. The natural frequency value which is obtained from the approximate shape function converges to its real value from top. The displacement values decrease as the FEM analysis results. The maximum displacement is calculated at $2.53 \mathrm{sec}$. While the maximum wave velocity value is $1.78 \mathrm{~m} / \mathrm{s}$, wind velocity reached $27.25 \mathrm{~m} / \mathrm{s}$ in the peak point of the tower. The results of the investigation for the FEM analysis showed that the highest value of von Mises stresses is $1.1639 \times 10^{10} \mathrm{~Pa}$ for $2.53 \mathrm{sec}$.

High structures cannot be modelled easily by the FEM because of node and elements number. In the present paper, it is observed that the Rayleigh model can be an alternative practical way of structural analysis.

\section{Conflicts of Interest}

The authors declare that there are no conflicts of interest regarding the publication of this paper.

\section{References}

[1] M. A. Silva, J. S. Arora, and R. M. Brasil, "Formulations for the optimal design of RC wind turbine towers," in Proceedings of the International Conference on Engineering Optimization (EngOpt 2008), Rio de Janeiro, Brazil, June 2008.

[2] W. Shi, J. Han, C. Kim, D. Lee, H. Shin, and H. Park, "Feasibility study of offshore wind turbine substructures for southwest offshore wind farm project in Korea," Renewable Energy, vol. 74, pp. 406-413, 2015.

[3] T. Seebai and R. Sundaravadivelu, "Response analysis of spar platform with wind turbine," Ships and Offshore Structures, vol. 8, no. 1, pp. 94-101, 2013.

[4] E. A. S. Linley, T. A. Wilding, K. Black, A. J. S. Hawkins, and S. Mangi, Review of the Reef Effects of Offshore Wind Farm Structures and Their Potential for Enhancement and Mitigation, Department for Business, Enterprise and Regulatory Reform (RFCA), London, UK, 2007.

[5] W. Liu, B. Tang, and Y. Jiang, "Status and problems of wind turbine structural health monitoring techniques in China," Renewable Energy, vol. 35, no. 7, pp. 1414-1418, 2010.

[6] S. E. Hirdaris, W. Bai, D. Dessi et al., "Loads for use in the design of ships and offshore structures," Ocean Engineering, vol. 78, pp. 131-174, 2014.

[7] V. J. Kurian, C. Y. Ng, and M. S. Liew, "Dynamic responses of truss spar due to wave actions," Research Journal of Applied Sciences Engineering and Technology, vol. 5, no. 3, pp. 812-818, 2013.

[8] E. D. Christensen, E. A. Hansen, L. Yde, N. J. Tarp-Johansen, H. Gravesen, and M. L. Damsgaard, "Wave loads on offshore wind turbine foundations in shallow water: engineering models vs. refined flow modelling," in Proceedings of the European Offshore Wind Conference, pp. 4-6, Berlin, Germany, December 2007.

[9] M. D. Kudale and A. R. Bhalerao, "Equivalent monochromatic wave height for the design of coastal rubblemound structures," Aquatic Procedia, vol. 4, pp. 264-273, 2015.

[10] P. Agarwal and L. Manuel, "Simulation of offshore wind turbine response for long-term extreme load prediction," Engineering Structures, vol. 31, no. 10, pp. 2236-2246, 2009.

[11] D. Witcher, "Seismic analysis of wind turbines in the time domain," Wind Energy, vol. 8, no. 1, pp. 81-91, 2005.

[12] I. Prowell, M. Veletzos, and A. Elgamal, "Full Scale Testing for Investigation of Wind Turbine Seismic Response," in Proceedings of the 7th world wind energy conference, Kingston, ON, Canada, 2008.

[13] C. Van der Woude and S. Narasimhan, "A study on vibration isolation for wind turbine structures," Engineering Structures, vol. 60, pp. 223-234, 2014.

[14] W. Y. Liu, "The vibration analysis of wind turbine bladecabin-tower coupling system," Engineering Structures, vol. 56, pp. 954-957, 2013.

[15] IEA Wind, IEA Wind: 2008 Annual Report, IEA Wind Energy Systems, International Energy Agency, PWT Communications, Boulder, CO, USA, 2009.

[16] S. Zhu and G. Moule, "Numerical calculation of forces induced by short-crested waves on a vertical cylinder of arbitrary cross-section," Ocean Engineering, vol. 21, no. 7, pp. 645-662, 1994. 
[17] S. E. Abdel Raheem, "Nonlinear behaviour of steel fixed offshore platform under environmental loads," Ships and Offshore Structures, vol. 11, no. 1, pp. 1-15, 2016.

[18] B. Y. Dağlı, M. E. Yiğit, and Ü. Gökkuş, "Behaviour of large cylindrical offshore structures subjected to wave loads," TEM Journal, vol. 6, no. 3, p. 550, 2017.

[19] F. K. Benra, H. J. Dohmen, J. Pei, S. Schuster, and B. Wan, "A comparison of one-way and two-way coupling methods for numerical analysis of fluid-structure interactions," Journal of Applied Mathematics, vol. 2011, Article ID 853560, 16 pages, 2011.

[20] M. E. Yigit, E. Gucuyen, and U. Gokkus, "Dynamic analysis of offshore steel wind turbine tower according to single degree of freedom system," in Proceedings of $3 \mathrm{rd} \mathrm{In-}$ ternational Steel Structures Conference, pp. 265-276, Gaziantep, Turkey, 2009.

[21] A. Korobenko, M. C. Hsu, I. Akkerman, J. Tippmann, and Y. Bazilevs, "Structural mechanics modeling and FSI simulation of wind turbines," Mathematical Models and Methods in Applied Sciences, vol. 23, no. 2, pp. 249-272, 2013.

[22] Y. Hu, C. Baniotopoulos, and J. Yang, "Effect of internal stiffening rings and wall thickness on the structural response of steel wind turbine towers," Engineering Structures, vol. 81, pp. 148-161, 2014.

[23] S. S. Khalid, L. Zhang, X. W. Zhang, and K. Sun, “Threedimensional numerical simulation of a vertical axis tidal turbine using the two-way fluid structure interaction approach," Journal of Zhejiang University SCIENCE A, vol. 14, no. 8, pp. 574-582, 2013.

[24] S. A. Yildizel, M. E. Yigit, and G. Kaplan, "Glass fibre reinforced concrete rebound optimization," Computer Modeling in Engineering and Sciences, vol. 113, no. 2, pp. 203-218, 2017.

[25] D. H. Kim and B. K. Han, "Simple method of vibration analysis of three span continuous reinforced concrete bridge with elastic intermediate support," Composites Research, vol. 17 , no. 3 , pp. $23-28,2004$.

[26] I. P. Ward, "Natural frequency analysis of offshore wind turbine monopiles," Proceedings of the Institution of Civil Engineers-Engineering and Computational Mechanics, vol. 169 , no. 4, pp. 196-208, 2016.

[27] C. Cruz and E. Miranda, "Evaluation of the Rayleigh damping model for buildings," Engineering Structures, vol. 138, pp. 324-336, 2017.

[28] ANSYS Fluent Users Guide, ANSYS, Canonsburg, PA, USA, 2013.

[29] M. M. K. Lee, "Strength, stress and fracture analyses of offshore tubular joints using finite elements," Journal of Constructional Steel Research, vol. 51, no. 3, pp. 265-286, 1999.

[30] K. Wei, S. R. Arwade, and A. T. Myers, "Incremental windwave analysis of the structural capacity of offshore wind turbine support structures under extreme loading," Engineering Structures, vol. 79, pp. 58-69, 2014.

[31] J. Van Der Tempel, Design of Support Structures for Offshore Wind Turbines, Ph.D. thesis, Delft University of Technology, Delft, Netherlands, 2006.

[32] J. E. Cermak, A. G. Davenport, E. J. Plate, and D. X. Viegas, Wind Climate in Cities, vol. 277, Springer Science \& Business Media, Berlin, Germany, 2013.

[33] CERC, Coastal Engineering Manual, Wave Mechanics, Part II, USA, Coastal Engineering Research Center, Vicksburg, MS, USA, 2002.

[34] A. Ergin, Coastal Engineering, Metu Press, Ankara, Turkey, 2010.
[35] R. M. Sorensen, Basic Coastal Engineering, vol. 10, Springer Science \& Business Media, Berlin, Germany, 2005.

[36] S. Chakrabarti, Handbook of Offshore Engineering, vol. 2, Elsevier, Amsterdam, Netherlands, 2005.

[37] Petroleum, ISO, Natural Gas Industries-Specific Requirements for Offshore Structures-Part 7: Station Keeping Systems for Floating Offshore Structures and Mobile Offshore Units. BS ISO, 19901-7, International Organization for Standardization, Geneva, Switzerland, 2005.

[38] Council, BSS, National Earthquake Hazard Reduction Program (NEHRP) Recommended Provisions for Seismic Regulations for 348 New Buildings and Other Structures-Part 2: Commentary (FEMA 450-2), Federal Emergency Management Agency, Washington, DC, USA, 2003.

[39] M. Papadrakakis, M. Fragiadakis, and N. D. Lagaros, Computational Methods in Earthquake Engineering, Springer, Berlin, Germany, 2011.

[40] E. Wang and T. Nelson, "Structural dynamic capabilities of ANSYS," in Proceedings of the ANSYS 2002 Conference, Pittsburg, PA, USA, April 2002.

[41] S. S. Rao and F. F. Yap, Mechanical Vibrations, vol. 4, Prentice Hall, Upper Saddle River, NJ, USA, 2011.

[42] R. S. Raja, "Coupled Fluid Structure Interaction Analysis on a Cylinder Exposed to Ocean Wave Loading," M.Sc. dissertation, Department of Applied Mechanics, Chalmers University of Technology, Gothenburg, Sweden, 2012.

[43] H. K. Versteeg and W. Malalasekera, An Introduction to Computational Fluid Dynamics-The Finite Volume Method, Pearson Education, Longman Scientific Technical, London, UK, 2007.

[44] P. Zhao, Y. Liang, Y. Wang, X. Li, and X. Lv, "Natural characteristics research of MW wind turbine tower," International Journal of Energy Science, vol. 3, no. 3, pp. 195199, 2013.

[45] W. Meng and W. Zhangqi, "The vibration frequencies of wind turbine steel tower by transfer matrix method," in Proceedings of the Third International Conference on Measuring Technology and Mechatronics Automation (ICMTMA 2011), pp. 995-998, Shanghai, China, 2011. 


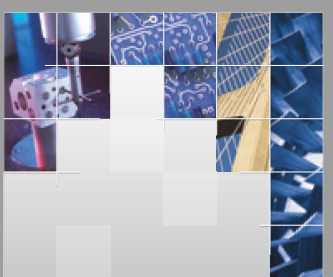

\section{Enfincering}
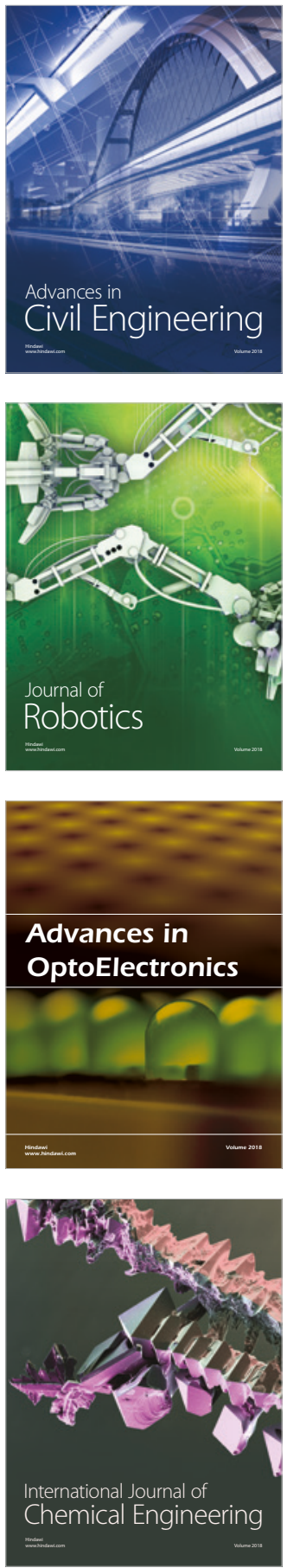

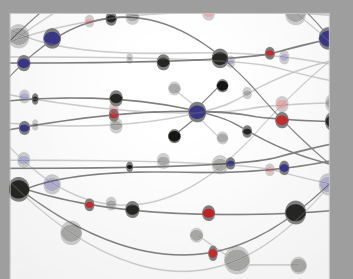

\section{Rotating \\ Machinery}

The Scientific World Journal

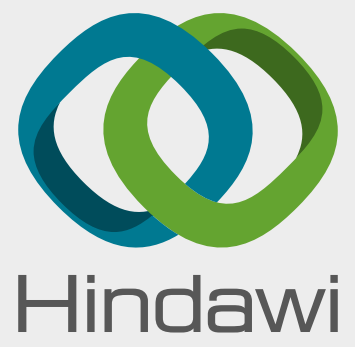

Submit your manuscripts at

www.hindawi.com
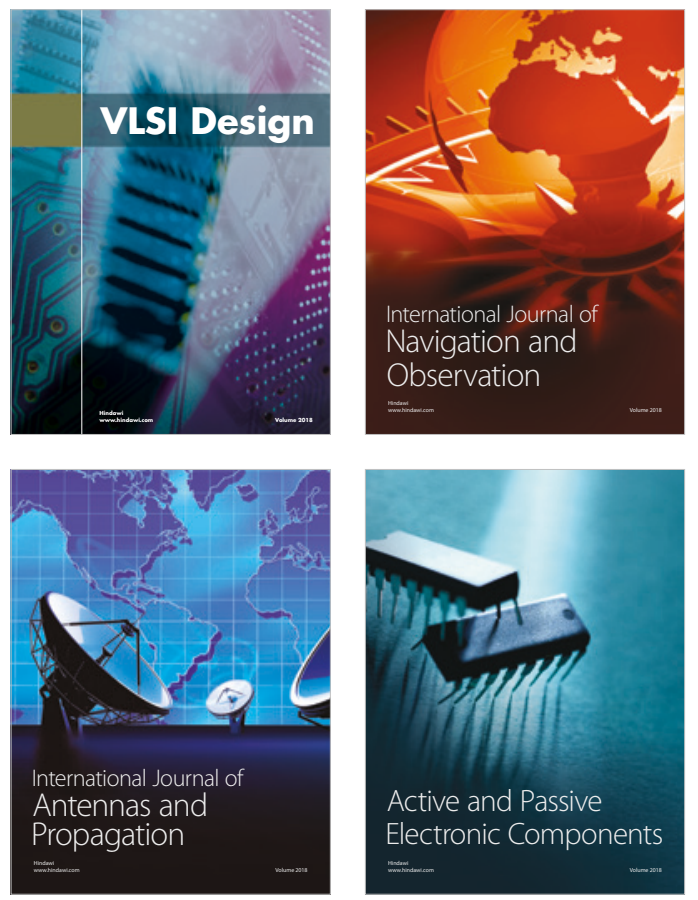
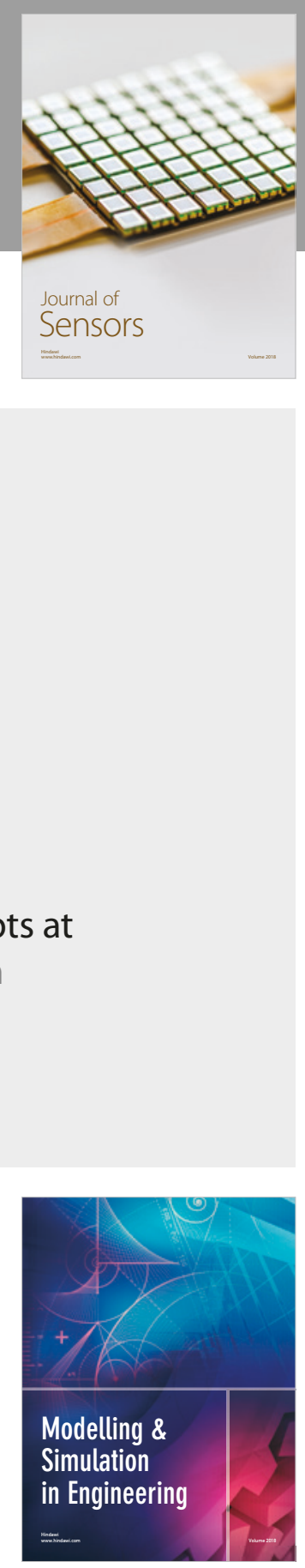

\section{Advances \\ Multimedia}
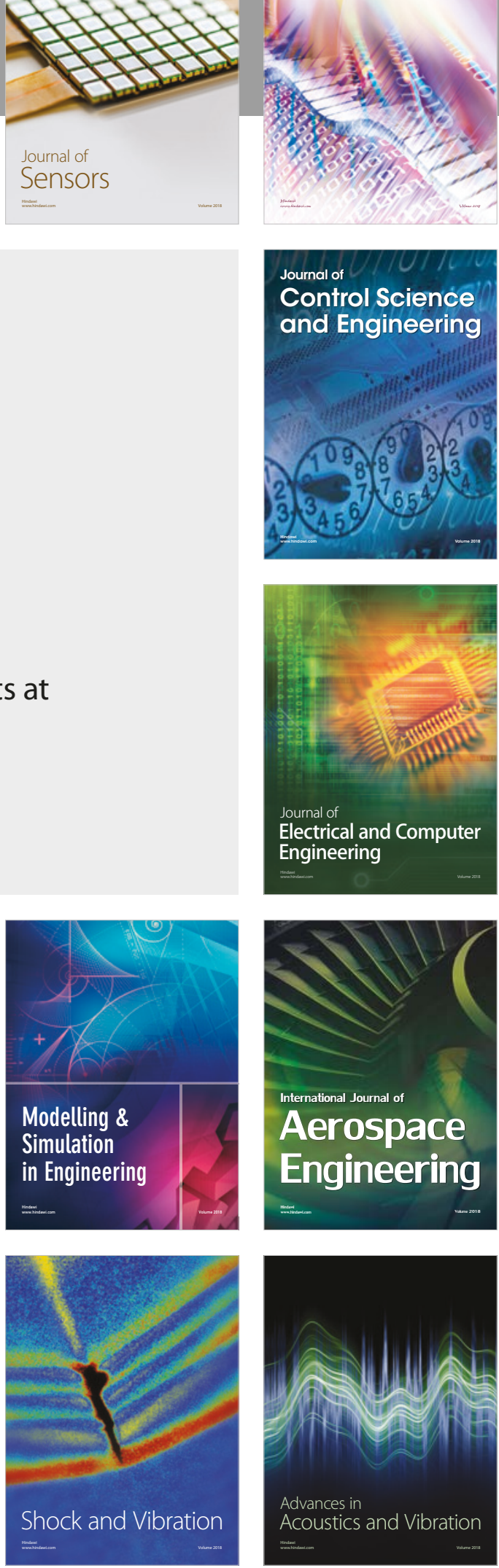